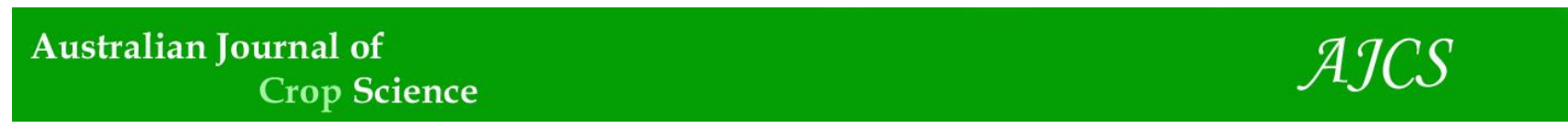

AJCS 11(04):395-405 (2017)

ISSN:1835-2707

doi: 10.21475/ajcs.17.11.04.pne272

\title{
Efficiency of drought tolerance indices under different stress severities for bread wheat selection
}

\author{
Sahar Bennani $^{1,2^{*}}$, Nasserlehaq Nsarellah ${ }^{1}$, Mohammed Jlibene ${ }^{3}$, Wuletaw Tadesse ${ }^{4}$, Ahmed Birouk $^{2}$ \\ Hassan Ouabbou ${ }^{1}$
}

${ }^{1}$ Plant breeding and Genetic Resources Conservation Department, National Institute of Agricultural Research, INRA, B.P. 415 Rabat, Morocco

${ }^{2}$ Agronomy and Veterinary Hassan II Institute, Madinate Al Irfane, B.P. 6202, Rabat, Morocco

${ }^{3}$ University Mohammed VI Polytechnique, UM6P, Bengherir, Morocco

${ }^{4}$ Biodiversity and Integrated Gene Management Program, International Center for Agricultural Research in the Dry Areas, B.P. 6299, Rabat, Morocco

\section{*Corresponding Author: sahar.bennani@gmail.com}

\begin{abstract}
Drought is a world-wide spread problem adversely affecting bread wheat production in rainfed agro-ecosystems. Development and identification of efficient selection criteria for developing drought tolerant wheat varieties with stable and high yield potential is of paramount importance. This study was carried out to evaluate 24 indices for selecting the best high yielding and drought tolerant cultivars, among 40 bread wheat genotypes, under four levels of stress intensities: no stress, mild $(0.25,0.35)$ and severe $(0.57)$. The mean productivity (MP), modified stress tolerance index (MSTIk), superiority index (Pi), mean relative performance (MRP), relative efficiency index (REI), geometric mean productivity (GMP), stress tolerance index (STI), harmonic mean (HARM) and relative decrease in yield (RDY) showed a high power of discrimination among genotypes, and expressed significant correlations with yields under both stress and non-stressed conditions at all stress intensities. This group of indices was capable to select the highest mean yield associated with the least mean variance at $20 \%$ selection pressure. However, as the stress intensity became greater $(>35 \%)$, the efficiency of these indices decreased, especially at high stress intensity (57\%), where only Pi and MP were still able to target the highest performances. MRP, REI, GMP, RDY and STI can be used interchangeably. Based on GGE analysis, the best performing genotypes were AUS30355, followed by Gladius, Amir-2 and AUS30354 that showed high yield and stability across all the environments. These genotypes are recommended for direct release and/or for use as parents in the breeding programs.
\end{abstract}

Received 5 Aug 2016; Revised 1 March 2017; Accepted 15 Feb 2017.

Keywords: Drought stress, grain yield, stress intensity, tolerance indices, Triticum aestivum.

Abbreviations: ATI_Abiotic Tolerance Index, DI_Drought Resistance Index, DRI_Drought Response Index, DTE_Drought Tolerance Efficiency, GM_Golden Mean, GMP_Geometric Mean Productivity, HARM_Harmonic Mean, MP_Mean Productivity, MRP_Mean Relative Performance, MSTIk1_Modified Stress Tolerance Index 1, MSTIk2_Modified Stress Tolerance Index 2, Pi_Superiority Index, RDI_Relative Drought Index, RDY_Relative Decrease in Yield, REI_Relative Efficiency Index, Red_Reduction, SSI_Stress Susceptibility Index, SSPI_Stress Susceptibility Production Index, STI_Stress Tolerance Index, TOL_Tolerance Index, YI_Yield Index, b_Coefficient of regression, bN_Relative adaptability to drought, SNPI_Stress/Non-stress Production Index.

\section{Introduction}

Bread wheat is one of the main crops for food security worldwide, representing about $95 \%$ of the wheat grown (Rajaram, 2000). In Morocco, bread wheat is mainly cultivated in rainfed agroecosystems ( $91 \%)$, characterized by highly variable and unpredictable precipitation pattern and large inter- annual fluctuations (Jlibene, 2009).

The Mediterranean region is identified as one of the most prominent drought hotspots in future climate change projections; especially in North Africa and Middle East (IPCC, 2007). In this context, the adoption of appropriate technological package, principally drought tolerant varieties and other cropping techniques such as fertilization and adequate mechanisation, may reduce the negative impact of the climate change (Gommes et al., 2009).
Drought tolerance is a complex trait, involving several morphological and physiological characters. Thus, efficient screening techniques are a pre-requisite for success in selecting desirable genotypes through any breeding program (Mitra, 2001). Until now, however, no efficient standard selection criteria have been proposed (Golabadi et al., 2006; Sio-Se Mardeh et al., 2006). Selection for yield automatically integrates all the known and unknown factors that contribute to drought tolerance (Richards, 1996). Nevertheless, the heritability of a quantitative trait such as grain yield is very low (Saba et al., 2001). In this perspective, several drought tolerance indices (Table 1) have been suggested to quantify tolerance and select the genotypes tolerant to stress on the basis of a mathematical relationship between yield under 
drought stress and non-stress conditions (Talebi et al., 2009; Pireivatlou et al., 2010).

A good drought tolerance index should have the power to discriminate between genotypes and must be able to identify superior ones in both drought prone and favorable environments (Saba et al., 2001; Farshadfar et al., 2012). However, the effectiveness of selection indices in differentiating resistant cultivars depends on the stress intensity of target environment varying over years and locations (Panthuwan et al., 2002; Farshadfar et al., 2012). The lines with outstanding performances over different stress intensities should be selected. Many studies (e.g. Moosavi et al., 2008; Talebi et al., 2009; Mohammadi et al., 2010; Mohammadi et al., 2011; Farshadfar and Elyasi, 2012; Farshadfar and al., 2012; Raman et al., 2012; Farshadfar et al., 2013; Golinezhad et al., 2014) have highlighted the efficiency of the indices for drought tolerance selection. However, none of these studies had treated all the major indices listed in the literature to establish the relationships between them and avoid the redundancy of their use. Moreover, the comparison of the effectiveness of these indices was based on simple statistics, mainly analysis of variance, correlation with yield combined with principal component analysis. Finally, the effect of target environment and stress intensity on the indices effectiveness was often mentioned but without further explanations.

In this perspective, the present study aimed to i) investigate the effectiveness of 24 drought indices in screening tolerant cultivars using more statistical proofs (heritability, repeatability, comparison of genotypes selection of different indices) under different drought stress intensities ii) evaluate the relationships among these indices; and iii) identify the highest yielding and the most stable genotypes.

\section{Results and Discussion}

\section{Comparative analysis of cropping seasons pattern}

The 2014 cropping season was characterized by a drier climate compared to the 2015 season for both experimental sites. The rainfall amount was $30 \%$ less in the stressed site (Sidi El Aidi; 185 and $258 \mathrm{~mm}$ during 2014 and 2015 seasons, respectively), and about $33 \%$ in the non-stressed site (Taoujdate; $278 \mathrm{~mm}$ versus $413 \mathrm{~mm}$ during 2014 and 2015, respectively) (Supplementary Table 1). According to growth stage, drought occurred for all environments at reproductive stage (heading and flowering stages) which is considered as drought of mid-season.

\section{Grain yield}

The Pearson's correlation coefficient showed highly significant association between crop yield and season rainfall $(r=0.914 ; p<0.001)$, indicating that the rainfall is the main source of variation among environments (Site $\mathrm{x}$ Year). The combined ANOVA indicated highly significant variability over years and sites; and among genotypes $(p<0.001)$ for grain yield (Supplementary Table 2). Moreover, the combined ANOVA over the 4 environments showed highly significant differences among genotypes and environments $(p<0.001)$ (Table 2). The Bonferroni test also showed significant differences among the 4 environments confirming our initial assumption (Supplementary Table 3). Accordingly, the stress intensity was used to compare among the four environments and generate the drought stress levels. Over the four environments, the highest mean grain yield (4.49 t/ha) was achieved at the favorable site (Taoujdate, 2015) during the 2015 season. Thus, it can be considered as the potential yield (Yp). During the 2014 season, the mean grain yield in the favorable site $(3.35 \mathrm{t} / \mathrm{ha})$ was $25 \%$ lower than the potential yield. Accordingly, Taoujdate in 2014 can be considered as the low moisture stress level (S1) at a stress intensity value of 0.25 . During 2015, the stressed site (Sidi El Aidi, 2015) recorded $2.91 \mathrm{t} / \mathrm{ha}$ yield level; with $35 \%$ reduction compared to its yield potential. This environment represents the mild stress level (S2), with stress intensity level of 0.35 . These two stress levels indicated that the genotypes experienced a mild drought stress $(<50 \%)$. The last stress condition (S3) was based on the grain yield of stressed site during 2014 season (1.93 t/ha). In this case, the stress intensity was stronger (0.57) with $57 \%$ of yield reduction compared to yield potential. This stress level can be considered as severe (more than $50 \%$ ) and occurred at Sidi El Aidi, 2014.

Correlation between yield potential and yield under different stress intensities was positive but not significant $(\mathrm{r}=$ $0.302, \mathrm{p}=0.059 ; \mathrm{r}=0.280, \mathrm{p}=0.08 ; \mathrm{r}=0.128, \mathrm{p}=0.432$, respectively for the 3 stressed levels). Thus, the improvement of yield potential may not automatically improve the yield under stressed conditions even under low to moderate stress intensity (Fernandez, 1992; Talebi et al., 2009; Mohammadi et al., 2010; Nouri et al., 2011; Farshadfar et al., 2013).

Heritability estimate measures the standing genetic variation of a population. Considering the grain yield over the four environments, the heritability was only $6 \%$. In literature, selection mainly for grain yield under drought stress conditions is difficult due to its low heritability resulting from variations in the intensity of the stress through the field (Blum, 1988; Saba et al., 2001). Thus, the improvement of yield under stress must combine a reasonably high yield potential with specific factors which would buffer against a severe yield reduction under stress (Chandler and Singh, 2008).

\section{Drought indices}

The results of combined ANOVA (Table 2) indicated that the drought tolerance indices DI, DTE, GMP, HARM, MP, MSTIk1, MSTIk2, Pi, RDY, Reduction, SNPI, SSPI, STI and TOL had significant differences among the three stress levels. This indicates that these indices were influenced by stress conditions, unlike indices ATI, DRI, GM, MRP, RDI, REI, SSI and YI which demonstrated their stability.

Based on one-way ANOVA (within each particular stress intensity) (Table 2), the drought indices DRI, GMP, HARM, MP, MRP, MSTIk1, RDY, REI, STI and YI showed significant differences among genotypes for all stress levels. These indices discriminate among genotypes performances in relation to water stress regardless of stress intensity. The indices RDI, DI, DTE, Reduction, SSI, SSPI, and TOL were significant only at 0.35 and 0.57 stress intensities, showing that they were not able to discriminate between genotypes under slight stress severity. On the other hand, SNPI, Pi, MSTIk2 and GM exhibited significant genotypic differences at moderate stresses $(0.25$ and 0.35$)$ and lost their efficiency at severe stress (0.57). Therefore, these indices are not useful in discriminating genotypes under severe stress. Finally, significant differences were noted between genotypes for ATI only at 0.25 and 0.57 but not at 0.35 stress intensity (Table 2). The heritability of calculated drought indices is the estimates of the average repeatability of the genetic expressions over the three moisture stress levels (Table 2). Almost all the drought indices showed an important heritability. 
Table 1. List of the 24 drought tolerance indices and formula.

\begin{tabular}{|c|c|c|c|}
\hline Index & Abbr. & Formula & References \\
\hline Mean productivity & MP & $(Y p i+Y s i) / 2$ & Rosielle and Hamblin (1981) \\
\hline Mean relative Performance & MRP & $\left(\frac{Y s i}{Y s}\right)+\left(\frac{Y p i}{Y p}\right)$ & Hossain et al. (1999) \\
\hline Stress susceptibility index & SSI & $\left(1-\left(\frac{Y s i}{Y p i}\right)\right) / S I$ Where $S I=1-\left(\frac{Y s}{Y p}\right)$ & Fischer and Maurer (1978) \\
\hline Stress tolerance index & TOL & $Y p i-Y s i$ & Rosielle and Hamblin (1981) \\
\hline Geometric Mean Productivity & GMP & $\begin{array}{l}\sqrt{Y p i \times Y s i} \\
Y s i) \quad Y p i\end{array}$ & Fernandez (1992) \\
\hline Relative efficiency index & REI & $\left(\frac{1 S t}{Y s}\right) \times\left(\frac{1 p \imath}{Y p}\right)$ & Hossain et al. (1999) \\
\hline Stress Tolerance Index & STI & $\begin{array}{l}(Y s i \times Y p i) /\left(Y p^{2}\right) \\
Y p i^{2}\end{array}$ & Fernandez (1992) \\
\hline Modified Stress Tolerance Index 1 & MSTIk1 & $\left(\frac{p^{2}}{Y p^{2}}\right) \times S T I$ & Farshadfar and Sutka (2002) \\
\hline Modified Stress Tolerance Index 2 & MSTIk2 & $\begin{array}{l}\left(\frac{Y S t^{-}}{Y s^{2}}\right) \times S T I \\
\times \text { Ypi } x Y s i\end{array}$ & Farshadfar and Sutka (2002) \\
\hline & HARM & $Z \times \overline{Y p i+Y s i}$ & \\
\hline Harmonic mean of yield & & & Dadbakhsh et al. (2011) \\
\hline Coefficient of regression & $\mathrm{b}$ & $\begin{array}{l}\sum Y i j Y j / \sum Y^{2} \text { where i refers to genotypes, } \mathrm{j} \text { environments, } \\
\mathrm{Y} \text { overall mean of all genotypes in all environments }\end{array}$ & Bansal and Sinha (1991) \\
\hline Relative adaptability to drought & $\mathrm{bN}$ & $b / a$ where $\mathrm{a}$ is the intercept of regression model & Karamanos and Papatheohari (1999) \\
\hline Yield Index & YI & $\begin{array}{l}Y S i / Y s \\
\sum_{i=1}^{n}(Y i j-M j)^{2} / 4 \text { where } \mathrm{I} \text { is the genotype, } \mathrm{j} \text { the } \\
\text { environment, } \mathrm{M} \text { the highest vielding genotype in the }\end{array}$ & Gavuzzi et al. (1997); Lin et al. (1986) \\
\hline Superiority Index & & environment $\mathrm{j}$ & Clarke et al. (1992); Lin et al. (1986) \\
\hline Reduction & Red & $(Y p i$ & Farshadfar and Javadinia (2011) \\
\hline Relative drought index & RDI & $\left(\frac{Y S i}{Y p i}\right) \div\left(\frac{Y S}{Y p}\right)$ & Fischer and Wood (1979) \\
\hline Drought Resistance Index & DI & $Y s i \times\left(\frac{Y S l}{Y p i}\right) / Y s$ & Lan (1998) \\
\hline Golden Mean & GM & $(Y p i+Y s i) /(Y p i-Y s i)$ & Moradi et al. (2012) \\
\hline Abiotic Tolerance Index & ATI & $\left(\frac{Y p i-Y s i}{\frac{Y p}{Y s}}\right) \times(\sqrt{Y p i \times Y s i}$ & Moosavi et al. (2008) \\
\hline Stress Susceptibility Percentage Index & SSPI & $\left(\frac{Y p i-Y s i}{2 \times Y p}\right) \times 100$ & Moosavi et al. (2008) \\
\hline Stress/non-stress Production Index & SNPI & $\begin{array}{l}\sqrt[3]{\frac{Y p i+Y s i}{Y p i-Y s i} \times \sqrt[3]{Y p i \times Y s i \times Y s i}} \\
(Y A-Y e s) / S e s \text { where } \mathrm{Y}_{\mathrm{A}} \text { is yield estimate by regression } \\
\text { in stress conditions; } \mathrm{Y}_{\mathrm{es}} \text { Real yield in stress conditions; } \mathrm{S}_{\mathrm{es}}\end{array}$ & Moosavi et al. (2008) \\
\hline Drought Response Index & & $=$ Standard error of estimated grain yield of all genotypes & Bidinger et al. (1987) \\
\hline Relative decrease in yield & RDY & $100-\left(\left(\frac{Y S i}{100}\right) \times Y p i\right)$ & Farshadfar and Elyasi (2012) \\
\hline Drought tolerance efficiency & DTE & $\left(\frac{Y s i}{Y p i}\right) \times 100$ & Fischer and Wood (1981) \\
\hline
\end{tabular}
Ysi: Yield under stress for genotype “i; Ypi: Yield under non-stress for genotype “i”; Ys: Mean of grain yield under stressed; Yp: Mean of grain yield under nonstress conditions.
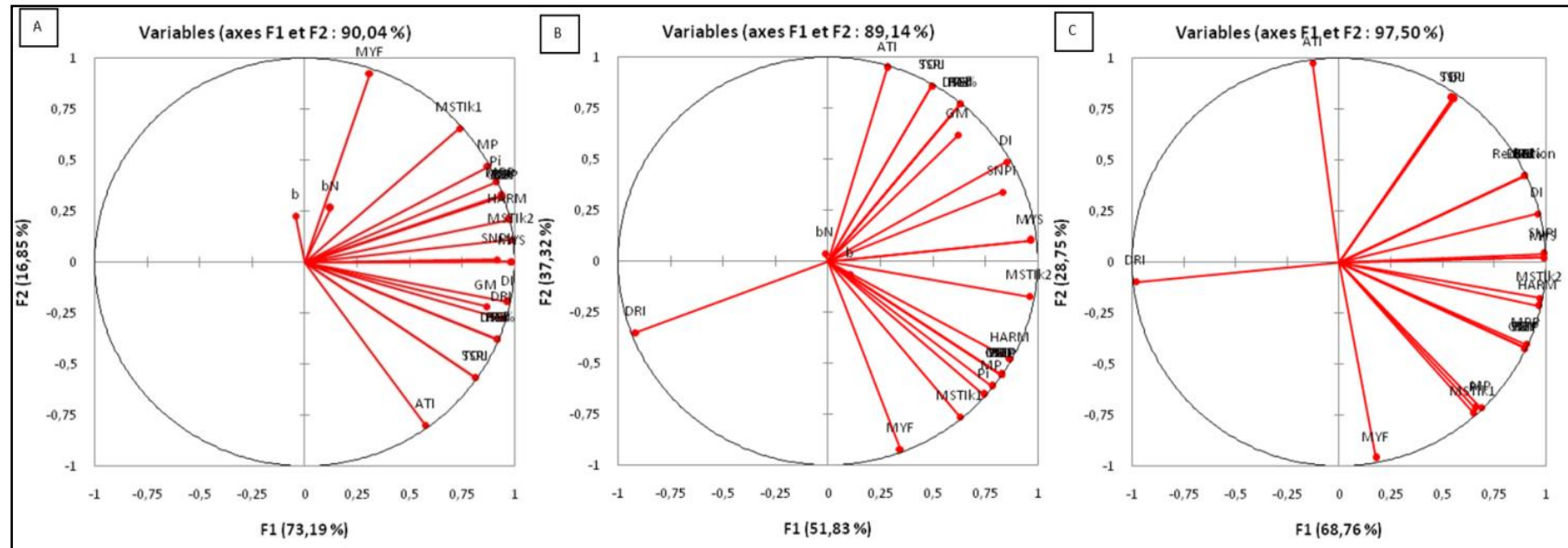

Fig 1. Biplot of drought indices based on Principal Component analysis at 0.25 (A), 0.35 (B) and 0.57 (C) stress severities, respectively. 
Table 2. Mean Square of analysis of variance of drought tolerance indices and grain yield for the 40 genotypes across stress levels, genotypes and their interactions

\begin{tabular}{|c|c|c|c|c|c|c|c|c|c|c|}
\hline \multirow{2}{*}{$\begin{array}{l}\text { Source of } \\
\text { variation }\end{array}$} & \multicolumn{6}{|c|}{ Two way ANOVA } & $\begin{array}{l}\text { ANOVA } \\
\text { S1 } 25 \%\end{array}$ & $\begin{array}{l}\text { ANOVA } \\
\text { S2 } 35 \%\end{array}$ & $\begin{array}{l}\text { ANOVA } \\
\text { S3 57\% }\end{array}$ & \multirow{2}{*}{$\begin{array}{c}\mathrm{h}^{2} \text { across mean } \\
\text { stress levels }\end{array}$} \\
\hline & Stress Level & $\begin{array}{l}\mathrm{VE} \\
(\%)\end{array}$ & $\begin{array}{l}\text { Genotype } \\
\text { (G) }\end{array}$ & $\begin{array}{l}\mathrm{VE} \\
(\%)\end{array}$ & SL x G & $\begin{array}{l}\mathrm{VE} \\
(\%)\end{array}$ & $\begin{array}{l}\text { Genotype } \\
\text { Effect }\end{array}$ & $\begin{array}{l}\text { Genotype } \\
\text { effect }\end{array}$ & $\begin{array}{l}\text { Genotype } \\
\text { effect }\end{array}$ & \\
\hline ATI & 3.36 & 5.67 & $12.46 * * *$ & 21.08 & 2.26 & 3.82 & $7.74 *$ & 6.66 & $1.89 *$ & 82 \\
\hline DI & $2.6 * * *$ & 60.84 & $0.43 * * *$ & 10.04 & 0.14 & 3.37 & 0.15 & $0.32 * *$ & $0.18 *$ & 66 \\
\hline DRI & 0.015 & 0.004 & 0.83 & 0.24 & $1.53 * * *$ & 0.44 & $1.54 * * *$ & $1.38 * *$ & $0.99 * *$ & 0 \\
\hline DTE & $36054.2 * * *$ & 85.84 & $2038.2 * * *$ & 0.48 & 448.9 & 0.11 & 737.8 & $1311.5^{*}$ & $605.3 *$ & 78 \\
\hline GM & 972.4 & 19.28 & $1695.8 * * *$ & 33.63 & $1624.7 * * *$ & 32.2 & $4433 * * *$ & $419.5 *$ & 83.65 & 4 \\
\hline GMP & $31.69 * * *$ & 79.55 & $1.39 * * *$ & 3.51 & 0.34 & 0.86 & $0.48 * * *$ & $1.005 * * *$ & $0.58 * *$ & 75 \\
\hline HARM & $46.81 * * *$ & 83.51 & $1.53 * * *$ & 2.74 & 0.49 & 0.87 & $0.52 * * *$ & $1.19 * * *$ & $0.75 * *$ & 68 \\
\hline MP & $16.17 * * *$ & 70.77 & $1.28 * * *$ & 5.59 & 0.19 & 0.84 & $0.45 * * *$ & $0.83 * * *$ & $0.39 * *$ & 85 \\
\hline MRP & 0.028 & 1.09 & $0.42 * * *$ & 16.64 & 0.099 & 3.9 & $0.12 * * *$ & $0.27 * * *$ & $0.23 * *$ & 77 \\
\hline MSTIk1 & $3.89 * * *$ & 53.96 & $0.63 * * *$ & 8.68 & 0.063 & 0.87 & $0.29 * * *$ & $0.36 * * *$ & $0.12 * *$ & 90 \\
\hline MSTIk2 & $1.87 * *$ & 32.23 & $1.01 * * *$ & 17.38 & 0.33 & 5.6 & $0.35 * * *$ & $1.002 * * *$ & 0.29 & 68 \\
\hline $\mathrm{Pi}$ & $11.89 * * *$ & 51.05 & $2.76 * * *$ & 11.87 & 0.55 & 2.37 & $0.81 * *$ & $2.32 * * *$ & 0.73 & 80 \\
\hline RDI & 0.007 & 0.31 & $0.57 * * *$ & 23.16 & 0.12 & 5.07 & 0.13 & $0.28 *$ & $0.33^{*}$ & 78 \\
\hline RDY & $0.134 * * *$ & 80.26 & $0.0066 * * *$ & 3.91 & 0.0015 & 0.9 & $0.003 * * *$ & $0.005 * * *$ & $0.002 * *$ & 77 \\
\hline REI & 0.011 & 0.45 & $0.43 * * *$ & 17.19 & 0.095 & 3.78 & $0.12 * * *$ & $0.27 * * *$ & $0.22 * *$ & 78 \\
\hline Red & $36054.2 * * *$ & 85.84 & $2038.2 * * *$ & 4.85 & 448.9 & 1.07 & 737.8 & $1311.5 *$ & $605.3 *$ & 78 \\
\hline SNPI & $174.63 * * *$ & 52.62 & $74.51 * * *$ & 22.45 & $38.36 * * *$ & 11.6 & $86.7 * * *$ & $59.73 * * *$ & 5.78 & 49 \\
\hline SSI & 0.27 & 6.03 & $1.86 * * *$ & 41.5 & 0.502 & 11.2 & 1.16 & $1.28 *$ & $0.19 *$ & 73 \\
\hline SSPI & $8454.2 * * *$ & 84.71 & $345.2 * * *$ & 3.46 & 80.5 & 0.81 & 120.1 & $188.4^{*}$ & $151.8 *$ & 77 \\
\hline STI & $3.31 * * *$ & 80.26 & $0.16 * * *$ & 3.91 & 0.037 & 0.9 & $0.07 * * *$ & $0.13 * * *$ & $0.041 * *$ & 77 \\
\hline TOL & $68.24 * * *$ & 84.7 & $2.79 * * *$ & 3.46 & 0.65 & 0.81 & 0.97 & $1.52 *$ & $1.23^{*}$ & 77 \\
\hline YI & 0.014 & 0.89 & $0.22 * * *$ & 14.29 & 0.093 & 6.1 & $0.05 * * *$ & $0.16 * * *$ & $0.17 * *$ & 57 \\
\hline Yield & $134.17 * * *$ & 94.25 & $1.62 * * *$ & 1.14 & $0.67 * *$ & 0.47 & $0.86 * * *$ & $1.48 * * *$ & $0.78 * *$ & \\
\hline
\end{tabular}

Table 3. Spearman's rank correlation between grain yields (Ys and Yp) and drought indices over the three stress levels.

\begin{tabular}{|c|c|c|c|c|c|c|}
\hline \multirow[t]{2}{*}{ Variables } & \multicolumn{2}{|c|}{ SL1 $25 \%$} & \multicolumn{2}{|c|}{ SL2 $35 \%$} & \multicolumn{2}{|c|}{ SL3 $57 \%$} \\
\hline & YS & YP & YS & YP & YS & YP \\
\hline YS & 1 & 0.239 & 1 & 0.309 & 1 & 0.152 \\
\hline YP & 0.239 & 1 & 0.309 & 1 & 0.152 & 1 \\
\hline MP & 0.683 & 0.837 & 0.862 & 0.714 & 0.658 & 0.820 \\
\hline MRP & 0.738 & 0.797 & 0.933 & 0.594 & 0.891 & 0.536 \\
\hline REI & 0.731 & 0.798 & 0.933 & 0.584 & 0.878 & 0.551 \\
\hline SSI & 0.688 & -0.494 & 0.913 & -0.066 & 0.893 & -0.229 \\
\hline TOL & 0.554 & -0.625 & 0.805 & -0.266 & 0.546 & -0.677 \\
\hline GMP & 0.731 & 0.798 & 0.933 & 0.584 & 0.878 & 0.551 \\
\hline STI & 0.731 & 0.798 & 0.933 & 0.584 & 0.878 & 0.551 \\
\hline MSTIk1 & 0.522 & 0.932 & 0.718 & 0.852 & 0.613 & 0.836 \\
\hline MSTIk2 & 0.952 & 0.483 & 0.989 & 0.404 & 0.969 & 0.327 \\
\hline HARM & 0.789 & 0.736 & 0.964 & 0.488 & 0.961 & 0.365 \\
\hline YI & 1.000 & 0.239 & 1.000 & 0.309 & 1.000 & 0.152 \\
\hline $\mathrm{Pi}$ & 0.632 & 0.862 & 0.894 & 0.636 & 0.621 & 0.811 \\
\hline Red & 0.688 & -0.494 & 0.913 & -0.066 & 0.893 & -0.229 \\
\hline RDI & 0.688 & -0.494 & 0.913 & -0.066 & 0.893 & -0.229 \\
\hline DI & 0.901 & -0.146 & 0.975 & 0.120 & 0.967 & -0.047 \\
\hline SSPI & 0.554 & -0.625 & 0.805 & -0.266 & 0.546 & -0.677 \\
\hline GM & 0.579 & -0.348 & 0.804 & 0.080 & 0.893 & -0.229 \\
\hline ATI & 0.360 & -0.789 & 0.560 & -0.554 & -0.099 & -0.986 \\
\hline SNPI & 0.782 & -0.009 & 0.871 & 0.306 & 0.998 & 0.139 \\
\hline RDY & 0.731 & 0.798 & 0.933 & 0.584 & 0.878 & 0.551 \\
\hline DTE\% & 0.688 & -0.494 & 0.913 & -0.066 & 0.893 & -0.229 \\
\hline DRI & -0.957 & 0.001 & 0.947 & 0.038 & -0.990 & -0.082 \\
\hline b & 0.075 & 0.032 & -0.024 & 0.148 & 0.555 & -0.670 \\
\hline $\mathrm{bN}$ & 0.018 & 0.005 & 0.135 & 0.233 & 0.893 & -0.229 \\
\hline
\end{tabular}



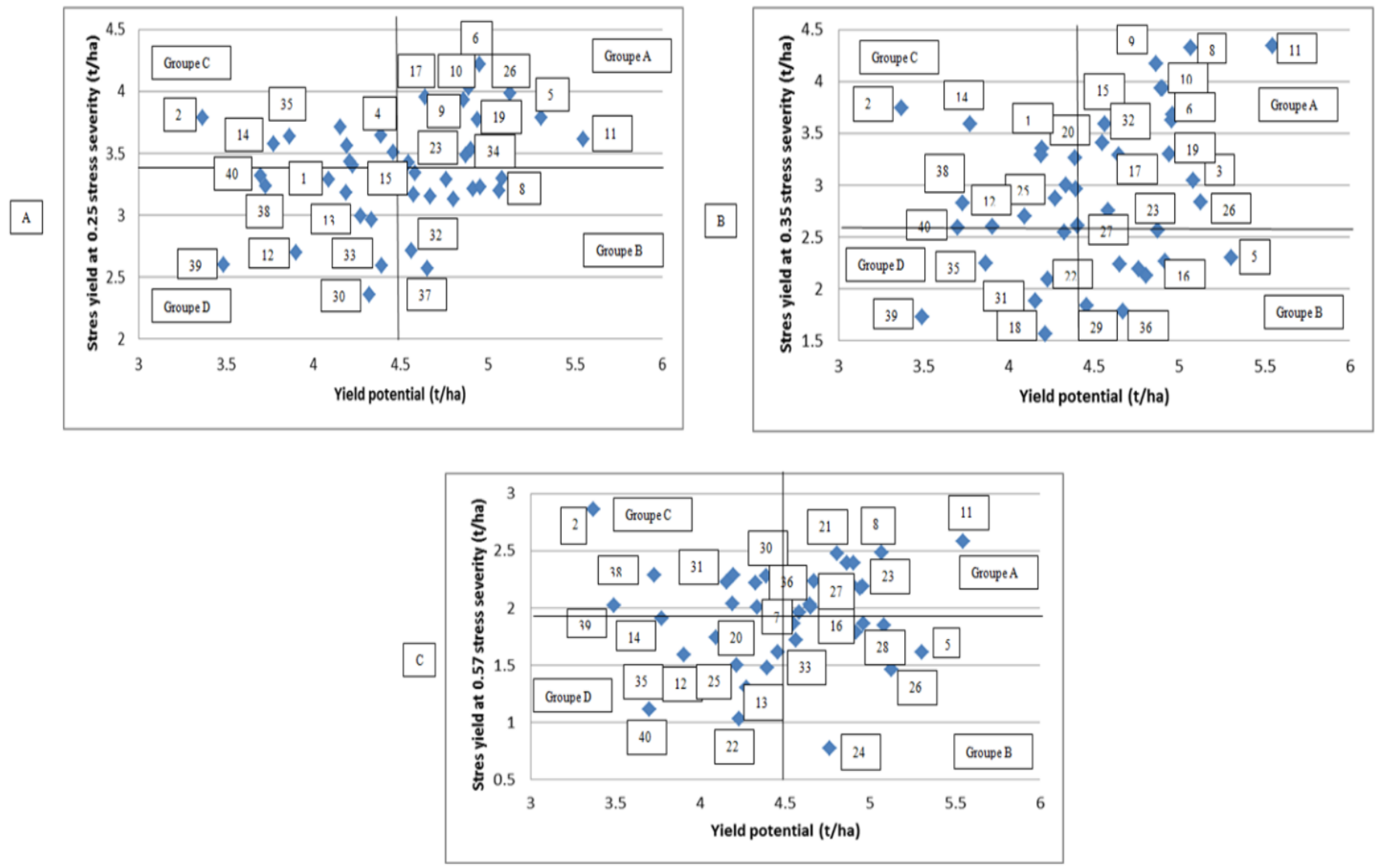

Fig 2. Relationships between Yield potential and Stress yield at 0.25 (A), 0.35 (B) and 0.57 stress severities (C).

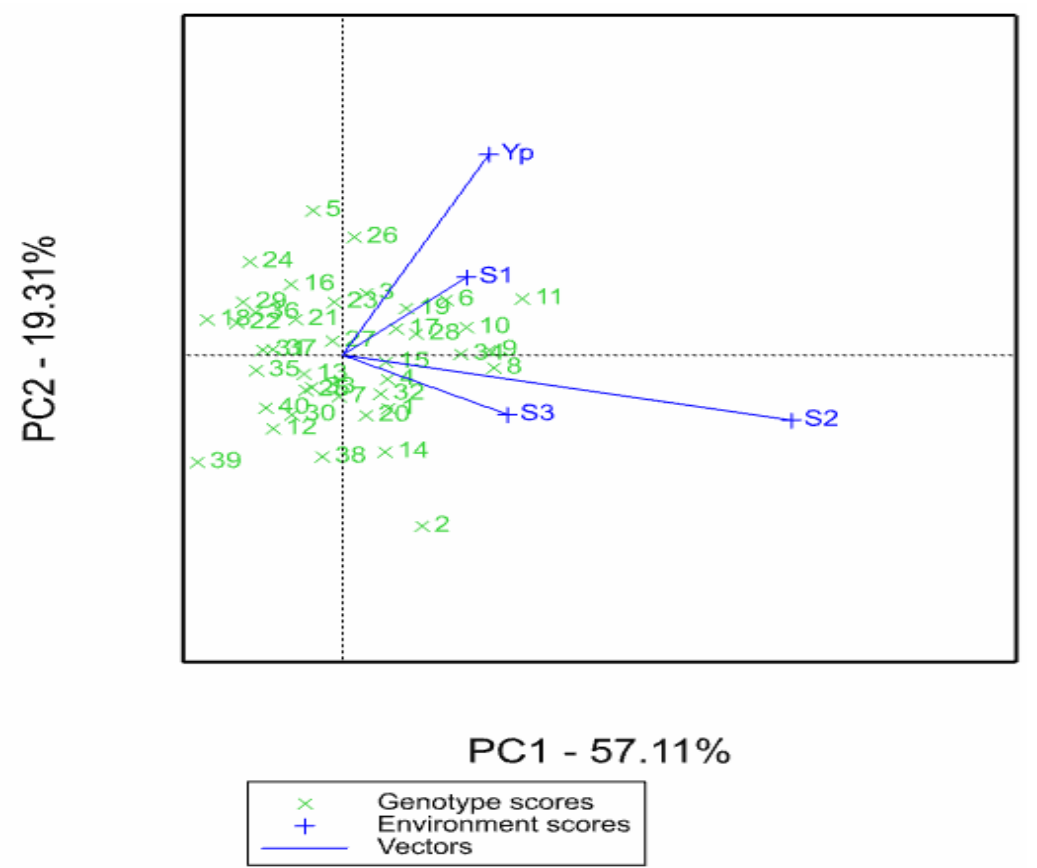

Fig 3. GGE analysis based on grain yield at four environments. 
Table 4. Mean yield and variance of the selected top $20 \%$ genotypes selection for the 24 drought indices at $0.25,0.35$ and 0.57 stress intensities.

\begin{tabular}{|c|c|c|c|c|c|c|c|c|c|}
\hline \multirow[b]{2}{*}{ Index } & \multicolumn{3}{|c|}{ Stress Level $25 \%$} & \multicolumn{3}{|c|}{ Stress Level $35 \%$} & \multicolumn{3}{|c|}{ Stress Level $57 \%$} \\
\hline & $\begin{array}{l}\text { Mean } \\
\text { yield }\end{array}$ & $\begin{array}{l}\text { Mean } \\
\text { variance }\end{array}$ & Top 20\% Genotypes selected & $\begin{array}{l}\text { Mean } \\
\text { yield }\end{array}$ & $\begin{array}{l}\text { Mean } \\
\text { variance }\end{array}$ & Top 20\% Genotypes selected & $\begin{array}{l}\text { Mean } \\
\text { yield }\end{array}$ & $\begin{array}{l}\text { Mean } \\
\text { variance }\end{array}$ & Top 20\% Genotypes selected \\
\hline MP & 4.47 & 0.36 & $6,10,26,17,9,2,5,19$ & 4.47 & 0.33 & $11,8,9,10,34,2,28,6$ & 3.68 & 1.75 & $2,11,8,21,9,34,38,1$ \\
\hline MRP & 4.47 & 0.36 & $11,5,26,3,8,28,6,19$ & 4.46 & 0.27 & $11,8,9,34,10,28,6,19$ & 3.62 & 1.51 & $11,8,21,34,9,6,10,19$ \\
\hline REI & 4.47 & 0.36 & $6,11,26,5,10,9,19,17$ & 4.46 & 0.27 & $11,8,9,34,10,28,6,32$ & 3.68 & 1.75 & $11,5,26,3,8,28,6,19$ \\
\hline GMP & 4.47 & 0.36 & $6,26,11,5,10,9,19,17$ & 4.46 & 0.27 & $11,8,9,34,10,28,6,32$ & 3.68 & 1.75 & $11,8,34,21,9,6,19,10$ \\
\hline STI & 4.47 & 0.36 & $6,26,5,11,10,9,19,17$ & 4.46 & 0.27 & $2,14,9,8,10,34,1,32$ & 3.68 & 1.75 & $11,8,21,34,9,6,10,2$ \\
\hline MSTIk2 & 4.47 & 0.36 & $2,14,35,40,31,38,17,6$ & 4.46 & 0.27 & $2,14,9,8,1,20,38,10$ & 3.60 & 1.46 & $11,8,34,9,21,6,19,10$ \\
\hline HARM & 4.47 & 0.60 & $2,14,35,40,31,38,1,17$ & 4.46 & 0.27 & $11,8,9,34,10,28,6,32$ & 3.62 & 1.51 & $11,8,21,34,9,6,10,19$ \\
\hline RDY & 4.47 & 0.36 & $6,26,5,11,10,9,19,17$ & 4.46 & 0.27 & $11,8,9,34,10,28,6,32$ & 3.68 & 1.75 & $11,8,21,34,9,6,10,19$ \\
\hline $\mathrm{Pi}$ & 4.46 & 0.40 & $6,26,5,11,10,9,19,17$ & 4.47 & 0.33 & $11,5,26,3,8,28,6,19$ & 3.68 & 1.75 & $2,38,39,14,1,31,30,4$ \\
\hline MSTIk1 & 4.46 & 0.44 & $11,5,26,6,10,19,9,3$ & 4.46 & 0.37 & $11,8,9,34,10,28,6,3$ & 3.68 & 1.75 & $2,38,39,1,31,4,21,30$ \\
\hline YI & 4.35 & 0.24 & $6,10,26,17,9,2,5,19$ & 4.39 & 0.25 & $11,8,9,34,10,28,6,32$ & 3.51 & 1.23 & $2,11,8,21,9,34,38,1$ \\
\hline DI & 4.08 & 0.09 & $26,5,6,11,10,9,19,34$ & 4.29 & 0.17 & $2,14,9,8,10,34,1,32$ & 3.42 & 1.09 & $2,38,39,1,31,4,21,30$ \\
\hline SNPI & 4.07 & 0.09 & $2,14,35,40,31,38,17,6$ & 4.38 & 0.22 & $11,8,9,10,34,2,28,6$ & 3.51 & 1.23 & $11,8,34,9,21,6,19,10$ \\
\hline $\mathrm{b}$ & 4.00 & 0.52 & $2,14,35,40,31,38,17,6$ & 3.66 & 0.74 & $26,2,38,40,23,16,28,33$ & 3.09 & 0.76 & $24,22,40,13,35,26,5,33$ \\
\hline bN & 3.96 & 0.57 & $2,6,35,14,17,31,10,9$ & 3.66 & 0.74 & $26,2,40,38,23,33,28,16$ & 3.19 & 0.82 & $2,11,21,8,9,38,34,1$ \\
\hline GM & 3.89 & 0.06 & $2,14,35,40,31,38,1,17$ & 4.16 & 0.17 & $2,8,9,14,11,10,34,32$ & 3.19 & 0.82 & $2,38,39,1,31,4,21,30$ \\
\hline SSI & 3.85 & 0.06 & $14,35,40,31,38,17,6,1$ & 4.14 & 0.15 & $2,14,9,8,1,20,38,10$ & 3.19 & 0.82 & $2,38,39,1,31,4,21,30$ \\
\hline Red & 3.85 & 0.06 & $2,14,35,40,38,31,1,39$ & 4.14 & 0.15 & $14,9,8,10,34,1,32,20$ & 3.19 & 0.82 & $2,38,21,1,8,11,31,4$ \\
\hline RDI & 3.85 & 0.06 & $14,35,6,31,17,10,40,9$ & 4.14 & 0.15 & $2,14,38,9,1,20,40,8$ & 3.19 & 0.82 & $2,38,39,14,1,31,30,4$ \\
\hline DTE & 3.85 & 0.06 & $6,26,5,11,10,9,19,17$ & 4.14 & 0.15 & $14,8,9,11,10,34,32,28$ & 3.19 & 0.82 & $2,39,38,14,40,35,12,31$ \\
\hline TOL & 3.76 & 0.05 & $2,14,35,40,31,38,17,6$ & 3.96 & 0.14 & $11,8,9,34,10,28,6,32$ & 3.09 & 0.76 & $11,8,21,34,9,6,10,19$ \\
\hline SSPI & 3.76 & 0.05 & $30,37,33,32,39,12,7,13$ & 3.96 & 0.14 & $2,14,9,8,10,34,1,32$ & 3.09 & 0.76 & $2,38,39,1,31,4,21,30$ \\
\hline ATI & 3.60 & 0.06 & $8,21,32,3,9,14,24,4$ & 3.79 & 0.15 & $2,8,14,9,11,6,10,34$ & 2.83 & 0.94 & $2,38,39,1,31,4,21,30$ \\
\hline DRI & 3.46 & 0.64 & $11,35,16,6,27,7,33,37$ & 4.31 & 0.19 & $11,8,9,34,10,28,6,19$ & 2.86 & 2.61 & $2,38,39,14,1,31,30,4$ \\
\hline
\end{tabular}


Table 5. List of the 40 bread wheat genotypes used for this study.

\begin{tabular}{llllll}
\hline Entry Code & Name & Origin & Entry Code & Name & Origin \\
\hline 1 & NEJMAH-11 & ICARDA & 21 & SB062 & CIMMYT \\
2 & NEJMAH-14 & ICARDA & 22 & SB109 & CIMMYT \\
3 & SHIHAB-12 & ICARDA & 23 & SB169 & CIMMYT \\
4 & AL-ZEHRAA-2 & ICARDA & 24 & SsrT02 & CIMMYT \\
5 & BAASHA-21 & ICARDA & 25 & SsrT09 & CIMMYT \\
6 & AMIR-2 & ICARDA & 26 & SsrT14 & CIMMYT \\
7 & ATTILA & CIMMYT & 27 & SsrT16 & CIMMYT \\
8 & SOKOLL & CIMMYT & 28 & SsrT17 & CIMMYT \\
9 & GLADIUS & AUSTRALIA & 29 & SsrW35 & CIMMYT \\
10 & AUS30354 & CIMMYT & 30 & SsrW47 & CIMMYT \\
11 & AUS30355 & CIMMYT & 31 & ARREHANE & Morocco \\
12 & AUS30518 & CIMMYT & 32 & ACHTAR & Morocco \\
13 & AUS30523 & CIMMYT & 33 & MARCHOUCH & Morocco \\
14 & QG-170-4.1 & CIMMYT & 34 & KANZ & Morocco \\
15 & QG-58-5.1 & CIMMYT & 35 & AMAL & Morocco \\
16 & HARTOG & AUSTRALIA & 36 & MASSIRA & Morocco \\
17 & DRYSDALE & AUSTRALIA & 37 & AGUILAL & Morocco \\
18 & SB003 & CIMMYT & 38 & BT05A104 & Morocco \\
19 & SB165 & CIMMYT & 39 & BT05A106 & Morocco \\
20 & SB069 & CIMMYT & 40 & RAJAE & Morocco \\
\hline
\end{tabular}

The highest heritability was expressed by MSTIk1 (90\%), MP (85 \%); ATI (82 \%); Pi (80\%); DTE, RDI, REI, Reduction (78 \%); SSPI, STI, TOL, RDY, MRP (77\%) and GMP $(75 \%)$. These indices are the most interesting as they show high repeatability across samples of environments and stress levels; indicating that selection based on them will be more fruitful. However, the lowest heritability was observed for $\mathrm{GM}(4 \%), \mathrm{bN}(16 \%)$ and the coefficient of regression $\mathrm{b}$ $(28 \%)$.

\section{Spearman correlations among grain yield (Yp and $Y s)$ and drought indices}

The index MP kept high correlation with both Yp and Ys at the three drought stress intensities (Table 3). Several studies stated the effectiveness of this widely used drought index under moderate stress (Golabadi et al., 2006; Sio-Se Mardeh et al., 2006; Mohammadi et al., 2010; Farshadfar and Elyasi, 2012; Farshadfar et al., 2012; Farshadfar et al., 2013) and severe stress (Moosavi et al., 2008; Talebi et al., 2009; Mohammadi et al., 2011; Moradi et al., 2012). MP represents the average yield under stress and non-stress conditions; allowing to describe yield variation under various moisture regimes (Rosielle and Hamblin, 1981). However, this index is maximized even when yield in either normal or stressed environment is too high (Najafian, 2009). The same findings were observed for (MSTIk1 and Pi) (Table 3) which is in agreement with numerous studies for MSTIk1 under moderate (Farshadfar and Elyasi, 2012; Farshadfar et al., 2012) and severe stress (Naghavi et al., 2013; Gholinezahed et al., 2014); and for Pi under moderate stress (Saba et al., 2001; Mohammadi et al., 2011) and severe stress (Mohammadi et al., 2010; Akçura and Ceri, 2011). However, their correlation with Ys became moderate at severe stress (0.57). This result can be explained by the fact that $\mathrm{Pi}$ formula is based on the distance mean square between the cultivar's response and the maximum response over environments (Lin and Binns, 1988). Hence, Pi instantly relates to the agronomic target of identifying genotypes with relatively high yield potential. Regarding MSTIk1, the equation is favoring mainly the yield potential power rather than the stress yield. MSTIk2 showed high positive correlation with Ys for all the stress intensities; while its relationship with Yp seemed to be always moderate (Table 3 ). This is in concordance with Farshadfar and Elyasi (2012); Farshadfar et al. (2012) and Gholinezhad et al. (2014) studies. This result can be explained by the formula which favors the yield under stress conditions (correction coefficient) rather than the yield potential. For the indices MRP, REI, GMP, STI, HARM and RDY, the correlation is strong with both yields; however, their correlation with Yp was high only at 0.25 stress intensity, but became moderate at 0.35 and 0.57 (Table 3). The results concerning HARM, GMP and STI are in agreement with Talebi et al. (2009); Mohammadi et al. (2011); Moradi et al. (2012) and Farshadfar et al. (2013). However, Rahmani et al. (2013) found an absence of correlation of Yp with HARM, GMP and STI under severe stress (0.6). Moreover, the association between yield and RDY was observed at slight moderate stress (Farshadfar and Elyasi, 2012); moderate (Farshadfar et al., 2013; Gholinezhad et al., 2014) and severe stress level (Gholinezhad et al., 2014). Similar to our findings, REI and MRP were useful in identifying genotypes with high yield potential in Bennani et al. (2016). All these indices have in common the yields product (Ys and Yp) in their equation and consider the effect of both yields in balance. Thus, the selected genotypes based on these indices are characterized by drought tolerance and will improve yield under stress conditions. Ys was positively and significantly correlated with SSI, RED, RDI, GM and DTE. However, the correlation of Yp with the same group was significant at 0.25 stress intensity; and non-significant at 0.35 and 0.57 (Table 3). These findings are in concordance with Mohammadi et al. (2010); Farshadfar et al. (2012); Moradi et al. (2012) and Rahmani et al. (2013). These indices are influenced by the variation between yields under stress and favorable conditions and permit to select drought tolerant genotypes. This can be explained by their formula which is favoring the stability more than the high yielding. Tolerance index (TOL) is computed as a tolerance degree. The positive correlation between TOL and Ys was strong at moderate stress levels $(0.25$ and 0.35$)$; but became moderate at 0.57 stress intensity (Table 3). These results are in agreement with Talebi et al. (2009) and Moradi et al. (2012) but in contradiction with the findings of Farshadfar et al. (2012) and Farshadfar et al. (2013) where there is no association even at moderate stress; 
and with Naghavi et al. (2013) and Rahmani et al. (2013) where high correlations were noted between the two components. However, strong negative correlation was found between TOL and Yp at all stress levels (Table 3) (Talebi et al., 2009; Akçura and Ceri, 2011; Moradi et al., 2012; Farshadfar et al., 2012; Rahmani et al., 2013). Sio-Se Mardeh et al. (2006) suggested that selection based on TOL could result in reduced yield under well-watered conditions (low Yp and Ys). TOL index only assess the plasticity of the genotypes under study, whereas a variety may rank first in both environments but still have higher TOL than the other varieties (Saba et al., 2001).

The indices YI, DI, SNPI and SSPI showed strong positive correlation only with Ys except the moderate correlation for SSPI at 0.57 stress intensity (Table 3 ). The same findings were found in Moosavi et al. (2008) and Gholinezhad et al. (2014). On the other hand, negative correlation characterized the relationship between Ys and DRI at 0.25 and 0.57 as stated by Farshadfar et al. (2012) and Ys with b and bN at severe stress level only (0.57) as indicated in Mohammadi et al. (2010) and Akçura and Ceri (2011) studies. The two former indices (YI and DI) formula are mainly focusing on yield under stress; while SNPI and SSPI rely on crop survivals in stress conditions revealing the relative yield stability of genotypes with changing conditions. The result of selection was appropriate for cultivars with potential stress tolerance, but may not be for cultivars with high yield in both conditions (Moosavi et al., 2008).

The index ATI showed a high significant negative correlation with $\mathrm{Yp}$ at 0.25 and 0.57 stress intensities $(-0.79$ and -0.99 respectively); while moderate correlation was observed between Yp and ATI at 0.35 (-0.55) (Table 3). These findings are in concordance with the results of Moosavi et al. (2008), Farshadfar et al. (2012), Rahmani et al. (2013) and Gholinezhad et al. (2014). However, significant positive correlation of 0.36 and 0.56 were observed between ATI and Ys at stress intensities of 0.25 and 0.35 respectively, which, however disappeared at 0.57 (Table 3 ). The same results were observed by Farshadfar and Elyasi (2012); Farshadfar et al. (2012); Rahmani et al. (2013). For this index, the yield stability is also more important than the high yield under non-stressed conditions. However, it has more emphasis on Yp than SSPI, SSI and TOL (Moosavi et al., 2008).

\section{Relationships between drought tolerance indices}

The principal component analysis was used to describe the interrelationships among all traits on the basis of overall pattern of the data (Fig 1). The bi-plot presents a whole picture about the interrelationships among the drought indices through the cosine of the angle between the vectors. The more the cosine between two indices is high, the more the traits (indices) are different, and the reverse is true (Yan et al., 2000). Low correlation between various indices suggests that each index may be a potential indicator of differential biological response to drought.

The two first principal components (PC) explained 89, 90 and $97.5 \%$ at $0.25,0.35$ and 0.57 stress intensities, respectively. The PC1 regrouped at the three stress levels Ys, MRP, REI, GMP, STI, MSTIk2, HARM, YI, DI, SNPI and RDY. This component can be called "Stress tolerance component". On the other hand, the PC2 showed consistent positive correlation with Yp and MSTIk1. This component can be called "Yield potential component" (Fig 1).

Over all the drought intensities, the indices MRP, REI, GMP, RDY and STI consistently showed (at all stress levels) an overlapping of their vectors. The indices HARM followed by MSTIk2 had strong correlation with this group (vector angle below $90^{\circ}$ ). The same observations were found for $\mathrm{Pi}$, MP and MSTIk1. These relationships became less strong at 0.57 compared to 0.25 and 0.35 stress intensities. These results were reported by Mohammadi et al. (2011); Farshadfar et al. (2012); Raman et al. (2012) and Rahmani et al. (2013). SNPI had also strong correlation with Ys at 0.25 stress intensity (below $90^{\circ}$ ); however, the overlap of vectors was observed at 0.35 and 0.57 stress levels. Furthermore, an overlapping of vectors was found between Ys and YI at all stress levels with strong correlation with SNPI (Fig 1). The observed relationships between YI and SNPI are consistent with those reported by Farshadfar and Elyasi (2012).

Moreover, the indices SSI, RED, RDI, and DTE also showed the overlapping of vectors (Fig 2). The same results were observed by Moosavi et al. (2008), Yarnia et al. (2011) and Nouraein et al. (2013). Strong correlations were observed between this group and GM and DI (below $90{ }^{\circ} \mathrm{C}$ ) especially at severe stress intensity (0.57) where we have an overlapping of vectors. SSPI and TOL had also collapsing of vectors as reported by Moosavi et al. (2008); Farshadfar and Elyasi (2012); Farshadfar et al. (2012); Naghavi et al. (2013); Rahmani et al. (2013).

The indices $\mathrm{b}$ and $\mathrm{bN}$ contributed consistently in the genetic variation observed only at 0.57 . The coefficient of regression (b) always had high correlation with $\mathrm{bN}$ as stated by Mohammadi et al. (2010). Overall, one of the indices MRP, REI, GMP, RDY and STI can be used interchangeably as an alternative for the others in genotypes selection. The same observation can be made for the group (SSI, RED, RDI, and DTE) and for the two indices $b$ and $b N$.

\section{Comparison of genotypes selection based on yield performances and drought indices}

For the three stress intensities, the genotypes were classified in the four Fernandez groups (A, B, C and D) based on the relationship between Yp and Ys (Fig 2). The group A includes high yield in both conditions. The group B contains high yield under non-stress conditions. The group $\mathrm{C}$ incorporates good yield under stressed conditions, while the group D integrates low yield in both conditions (Fernandez, 1992).

Overall, the genotypes $6,9,10,11,17,19$ and 34 belonged to the group $\mathrm{A}$ at the three stress levels and can be considered as high yielding and stable genotypes across all the environments studied. Based on GGE outputs, the GGE biplot explained about $76 \%$ of the total variation (Fig 3). The environment played the most important part in yield variation (97\%), while, based on total sum of squares (Data not Shown), only $1.2 \%$ and $0.47 \%$ of variation were attributed for both genotypes and interaction effects. The genotype G11 followed by G9, G6 and G10 had the best performances of high yield and stability across all the environments.

Each index provides proper genotypes ranking according to its appropriate formula. At 0.25 stress intensity, in comparison with Fernandez groups outputs (Fig 2), the indices MP, MRP, REI, GMP, STI, MSTIk2, HARM, Pi and RDY selected efficiently the group A $(6,11,26,5,10,9,19$, 17) when considering $20 \%$ of selection pressure (Table 4). The indices MISTk1 and Yi selected the group A; but MSTIk1 integrated genotype 3 which belongs to group B instead of genotype 17; while Yi selected genotype 2 belonging to the group $\mathrm{C}$ instead of genotype 11. At 0.35 stress intensity (Table 4), the indices MP, REI, GMP, STI, MSTIk1, Pi, and RDY were composed at $87.5 \%$ from group 
A, and one genotype from group B (G21) (Fig 2). MRP and HARM were formed mainly by group A $(75 \%)$ and one genotype from group B (G21) and group C (G2). At 0.57 stress intensity (Table 4), the indices MP and Pi selection was based mainly on group A $(87.5 \%)$ and one genotype from group B (G28) (Fig 2). The indices MRP, REI, GMP, STI, MSTIk1, MSTIk2, HARM, RDY, YI, DRI selection was composed by $75 \%$ of group A. The index SNPI selection was formed by $62.5 \%$ of group A, $25 \%$ of group B and one genotype from group D (G14); while DI selection was constituted by $62.5 \%$ of group $\mathrm{A}$, and the rest of genotypes belonged equally to the remaining groups (B, C and $\mathrm{D})$. The remaining indices were not able to target the group $\mathrm{A}$ and didn't select more than $50 \%$ of the $20 \%$ genotypes selection pressure (Table 4).

Regarding the mean yield and mean variance of the genotypes selected (Table 4), the indices MP, MRP, REI, GMP, STI, MSTIk2, HARM, RDY, Pi and MSTIk1 showed the highest mean yield $(4.47 \mathrm{t} / \mathrm{ha})$ associated with mean variance $(0.37)$ at 0.25 of stress level. At 0.35 , the same indices exhibited the best mean yield that didn't differ from the one at $0.25(4.46 \mathrm{t} / \mathrm{ha})$ but the variance was reduced (0.29). However, at severe stress (0.57), the reduction of mean yield by $18 \%$ was obvious and reached $3.66 \mathrm{t} / \mathrm{ha}$ for the same indices and showed an increase of variance (1.67).

\section{Selection of the best drought tolerance indices}

The objective of this study was to identify the best drought yield indices able to identify breeding lines with superior performances over various stress severities (non-stress, slight stress, moderate stress, severe stress). These indices must better express genetic differences, high heritability and repeatability across samples of the environments, high correlation with yields under stressed and non-stress conditions and must target the highest performances (group A) (Fernandez, 1992; Mitra, 2001; Bennani et al., 2016). Our study aims to study all the known drought indices cited in the literature, under a contrasting inter annual and inter site Moroccan climate, to elucidate their efficiency under three drought scenarios based on more statistical proofs.

The drought indices MP, MSTIk1, Pi, MSTIk2, MRP, REI, GMP, STI, HARM and RDY showed high significant differences among genotypes at each stress level, showing a high degree of discrimination. They expressed significant correlation with both yields (potential and stressed yields) at all stress intensities. The index MP kept high correlation at the three stress intensities. However, the correlation of MSTIk1 and Pi with Ys was moderate at severe stress (0.57); while the indices (MRP, REI, GMP, STI, HARM and RDY) showed moderate association with Yp at 0.35 and 0.57 . This selection of indices also exhibited the highest mean yield for all drought intensities associated with the lowest mean variance of genotypes selected at $20 \%$ of pressure. Regarding Fernandez groups selection (1992) at $20 \%$ selection pressure, the same indices (MP, MSTIk1, Pi, MSTIk2, MRP, REI, GMP, STI, HARM and RDY) selected efficiently the group A at 0.25 except MSTIk1 which integrated one genotype from group B to its list of selection. Many studies have reported the effectiveness of these indices in selecting high yielding and drought tolerant genotypes (Rosielle and Hamblin, 1981; Fernandez, 1992; Ramirez and Kelly, 1998; Hohls, 2001; Golabadi et al., 2006; Jafari et al., 2009; Talebi et al., 2009; Mohammadi et al., 2010; Farshadfar et al., 2012; Raman et al., 2012). However, the drought indices are influenced by stress intensity and difference in drought patterns among locations and years.
Therefore, when the stress became more intense, these indices became less efficient, as stated also by Mohammadi et al. (2010). In fact, At 0.35 stress severity, MP, REI, GMP, STI, MSTIk1, Pi, RDY remained the best and selected 7 genotypes from group A out of 8 , and one genotype from group B; while MRP and HARM selected 6 genotypes from group $\mathrm{A}$ and incorporated 2 genotypes respectively from group B and group C. At severe stress (0.57), only MP and Pi kept high performances by selecting 7 genotypes from group A out of 8; while MRP, REI, GMP, STI, MSTIk1, MSTIk2, HARM and RDY selected 6 genotypes from group A and 2 genotypes from group B and C respectively.

Overall, based on the statistical analysis, the indices MP, REI, GMP, STI, MSTIk1, Pi and RDY represent the appropriate selection criteria for drought tolerance; especially MP and Pi. As REI, GMP, STI and RDY can be used interchangeably, a cross selection based on MP REI, MSTIk1 and $\mathrm{Pi}$ should be the best combination for an efficient selection of the best performances under drought stress.

\section{Materials and Methods}

\section{Plant materials and experimental design}

Forty spring bread wheat genotypes, from diverse origins (Australia, Morocco, ICARDA, CIMMYT) (Table 1), were chosen based on their broad range of response to drought stress and yield performance and were planted in Randomized Complete Block design (RCBD) with three replications in two contrasting experimental fields (stressed and non-stressed) during 2013-14 and 2014-15 cropping seasons. Each combination "Site x Year" was considered as an environment.

Each plot $\left(9 \mathrm{~m}^{2}\right)$ was composed of 6 rows of $5 \mathrm{~m}$ length, with inter-row distance of $0.25 \mathrm{~m}$. The sowing was performed in late November and harvesting was carried out on mid-May for stressed fields and mid-June in non-stressed experimental site. The fertilizers (N18 - P46 - K00) and Urea $(33.5 \%)$ were applied at a rate of 1 quintal/ha before planting and tillering stage respectively. The plants were protected against foliar diseases by applying fungicides (Impact) at a rate of $1 /$ ha twice (at booting and heading stages), and weeds were controlled manually and by herbicides using Cossak (11/ha) at the beginning of the season and Mustang (11/ha) at reproductive stages.

\section{Experimental Sites}

The study considered two contrasting experimental sites in terms of long term average rainfall, namely "Taoujdate" and "Sidi El Aidi", belonging to the National Institute of Agricultural Research of Morocco. The favorable site (Taoujdate) is located at $33^{\circ} 55^{\prime} 49^{\prime}$ 'N latitude, $5^{\circ} 16^{\prime} 33^{\prime}$ ' $\mathrm{W}$ longitude, at an elevation of $550 \mathrm{~m}$ above sea level. The soil is deep clay. The yearly average maximum and minimum temperatures are $19.9^{\circ} \mathrm{C}$ and $2.8^{\circ} \mathrm{C}$ respectively, and average annual rainfall is $470 \mathrm{~mm}$. The "Sidi El Aidi" station represents the stressed semi-arid site with $300 \mathrm{~mm}$ as mean rainfall. It is located at $33^{\circ} 07^{\prime} 16^{\prime}$ ' $\mathrm{N}$ latitude, $7^{\circ} 37^{\prime} 44^{\prime \prime}$, longitude, at an elevation of $240 \mathrm{~m}$. The soil is deep clay. The yearly average maximum and minimum temperatures are $19.5^{\circ} \mathrm{C}$ and $-4^{\circ} \mathrm{C}$ respectively.

\section{Statistical analysis}

The grain yield of each plot was evaluated based on $9 \mathrm{~m}^{2}$, and converted to the standard unit at metric ton per hectare $(\mathrm{t} / \mathrm{ha})$. 
The stress intensity calculation was based on the formula: $S I=1-\left(\frac{Y s}{Y p}\right)$ considering all the combinations between the yields across years and sites. The Yp refers to potential yield at the favorable season in Taoujdate, while Ys is the stressed yield. We assume that rainfall is the main driving force of yield in these environments. Then, based on the mean grain yield across trials under non-stress, moderate and severe stress conditions, conventional drought tolerance indices were calculated (Table 1 ).

The combined analysis of variance (ANOVA) was carried out for grain yield considering the effects of three factors (years, sites and genotypes) according to the model:

$Y=$ Year + Site + Bloc $($ site $)+$ Genotypes + Genotype $\times$ Year + Genotype $\times$ Site + Genotype $\times$ Year $\times$ Site + Error

The second model of two-ways ANOVA was used for single environments for grain yield and drought indices using the model:

$$
\begin{aligned}
& Y=\text { Stress Level or environment + Genotypes } \\
& + \text { Genotype } \\
& \times \text { Stress Level or environment } \\
& + \text { Error }
\end{aligned}
$$

Finally, the third model was used for each stress level separately to detect the genotypic effect per stress level using the model:

$$
Y=\text { Genotype }+ \text { Bloc }+ \text { Error }
$$

For each combined ANOVA, the magnitude of variation attributable to each factor was estimated as percentage of variance explained (VE \%) of total sum of squares.

The broad sense heritability of grain yield was computed based on mean square variations according to the formula developed by Lush (1940) and Robinson et al. (1949) as follows:

$$
h^{2}(\%)=\left(\frac{V g}{V p}\right) * 100
$$

Where, $\mathrm{Vg}$ is the genotypic variance

$\mathrm{Vp}$ is the phenotypic variance

For ranking the genotype that had the least of SSI, TOL, Pi, SSPI, ATI, RDY, Reduction, $b N$ and $b$ indices value and the most of HARM, MP, MRP, REI, GMP, STI, MSTIk1, MSTIk2, YI, RDI, DI, GM, SNPI, DTE and DRI earned the first position (rank 1).

The ANOVA was performed using GENSTAT software (Discovery edition 3, VSN International, UK). The correlation and PC analysis were carried out using XLSTAT (Free trial version 2015, Addinsoft, Inc., Brooklyn, NY, USA); while the GGE analysis was performed using BMS software.

\section{Conclusion}

Significant differences among genotypes in grain yield were observed across the four environments (non-stress, 0.25, 0.35 and 0.57 stress intensities). Over all the stress intensities, a cross selection based on the indices REI, MSTIk1, GMP, STI, RDY, MP and Pi (especially the 2 last ones) can enable breeders to select efficiently advanced bread wheat lines. The indices REI, GMP, STI and RDY can be used interchangeably. Based on indices selection and GGE analysis, AUS30355, Gladius, Amir-2 and AUS 30354 were the best high yielding and drought tolerant genotypes among the 40 lines evaluated. These genotypes are recommended for direct release and/or parentage purposes in the breeding programs.

\section{Acknowledgement}

We would like to thank the two experimental stations staff for their contribution to the release of field work. We are also grateful for the financial and technical support provided by ICARDA and INRA.

\section{References}

Akcura M, Ceri S (2011) Evaluation of drought tolerance indices for selection of Turkish oat (Avena sativa L.) landraces under various environmental conditions. ZEMDIRBYSTE 98(2): 157-166.

Bansal KC, Sinha SK (1991) Assessment of drought resistance in 20 accessions of Triticum aestivum L. and related species, total dry matter and grain yield stability. Euphytica 56: 7-14.

Bennani S, Birouk A, Nsarellah N, Jlibene M, Ouabbou H (2016) Efficiency of selection indices in screening bread wheat lines combining drought tole rance and high yield potential. J Plant Breed Crop Sci 8 (5): 72-86.

Bidinger FR, Mahalakshmi V, Rao GDP (1987) Assessment of drought resistance in pearl millet (Pennisetum americanum (L) Leeke). I Factors affecting yields under stress. Aust J Agr Sci. 38: $37-48$.

Blum A (1988) Breeding crop varieties for stress environments. Plant Sci. 2: 199-238.

Chandler SS, Singh TK (2008) Selection criteria for drought tolerance in spring wheat (Triticum aestivum L.). In: Appels R, Eastwood R, Lagudah E, Langridge P, Mackay LM (Eds.) Proceedings of the 11th international wheat genetics symposium. Sydney, Australia. pp. 1-3.

Clarke JM, De Pauw RM, Townley-Smith TM (1992) Evaluation of methods for quantification of drought tolerance in wheat. Crop Sci. 32:732-728.

Dadbakhsh A, Yazdansepas A, Ahmadizadeh M (2011) Study drought stress on yield of wheat (Triticum aestivum L.) genotypes by drought tolerance indices. Adv Environ Biol. 5 (7): $1804-1810$.

Farshadfar E, Sutka J (2002) Multivariate analysis of drought tolerance in wheat substitution lines. Cereal Res Commun. 31: 33-39.

Farshadfar E, Javadinia J (2011) Evaluation of chickpea (Cicer arietinum L.) genotypes for drought tolerance. Seed Plant Improv J. 27(4): 517-537.

Farshadfar E, Elyasi P (2012) Screening quantitative indicators of drought tolerance in bread wheat (T. aestivum) landraces. Pelagia Research Library. Eur J Exp Biol. 2 (3): 577-584.

Farshadfar E, Pour Siahbidi MM, Pour Aboughadareh AR (2012) Repeatability of drought tolerance indices in bread wheat genotypes. Inter J Agri Crop Sci. 4(13): 891-903.

Farshadfar E, Mohammadi R, Farshadfar M, Dabiri S (2013) Relationships and repeatability of drought tolerance indices in wheat-rye disomic addition lines. Aust J Agr Sci. 7 (1): 130138.

Fernandez GCJ (1992) Effective selection criteria for assessing plant stress tolerance. In: Kuo CG (eds). Adaptation of Food Crops to Temperature and Water Stress. International symposium, Taiwan, 13-18 August 1992.

Fischer RA, Maurer R (1978) Drought resistance in spring wheat cultivars. Aust J Agr Res. 29: 897-912.

Fischer RA, Wood JT (1979) Drought resistance in spring wheat cultivars III. Yield association with morphological traits. Aust J Agr Res. 30: 1001-1020.

Fischer KS, Wood G (1981) Breeding and selection for drought tolerance in tropical maize. Symposium on principles and methods in crop improvement for drought resistance with emphasis on rice, IRRI, Philippines, 1981.

Gavuzzi P, Rizza F, Palumbo M, Campaline RG, Ricciardi GL, Borghi B (1997) Evaluation of field and laboratory predictors of drought and heat tolerance in winter cereals. Can J Plant Sci. 77: 523-531. 
Gholinezhad E, Darvishzadeh R, Bernousi I (2014) Evaluation of Drought Tolerance Indices for Selection of Confectionery Sunflower (Helianthus anuus L.) Landraces under Various Environmental Conditions. Not Bot Horti Agrobo. 42(1):187201.

Golabadi M, Arzani A, Mirmohammadi Maibody SAM (2006) Assessment of drought tolerance in segregating populations in durum wheat. Afr J Agric Res. 1 (5):162-171.

Gommes R, El Hairech T, Rosillon D, Balaghi R, Kanamaru H (2009) Impact of climate change on agricultural yields in Morocco. In: FAO (Eds). World Bank-Morocco study on the impact of climate change on the agricutural sector.

Hohls T (2001) Conditions under which selection for mean productivity, tolerance to environmental stress or stability should be used to improve yield across a range of contrasting environments. Euphytica 120 (2): 235-245.

Hossain ABS, Sears AG, Cox TS, Paulsen GM (1999) Desiccation tolerance and its relationship to assimilate partitioning in winter wheat. Crop Sci. 30: 622-627.

IPCC (2007) Climate change 2007: The physical science basis: contribution of working group I to the fourth Assessment report of the intergovernmental panel on climate change. Cambridge: Cambridge University press: 847-940.

Jafari A, Paknejad F, Jami Al-Ahmadi M (2009) Evaluation of selection indices for drought tolerance of corn (Zea mays L.) hybrids. Int J Plant Prod. 3(4): 33-38.

Jlibene M (2009) Options génétiques d'adaptation du blé tendre au changement climatique. INRA-Morocco (Eds). Variétés à résistance multiple: sécheresse, cécidomyie, septoriose, rouilles brune et jaune. INRA. Morocco.

Karamanos AJ, Papatheohari AY (1999) Assessment of drought resistance of crop genotypes by means of the water potential index. Crop Sci. 39: 1792-1797.

Lan J (1998) Comparison of evaluating methods for agronomic drought resistance in crops. Acta Agr Bor-Occid Sinic. 7: 8587.

Lin CS, Binns MR (1988) A superiority measure of cultivar performance for cultivar x location data. Can J Plant Sci. 68: 193-198.

Lin CS, Binns MR, Lefkovitch LP (1986) Stability analysis: where do we stand? Crop Sci. 26: 894-900.

Lush JL (1940) Intrasine correlation and regression of offspring on dams as a method of estimating heritability of character. Proc Amer Soc Anim Nutr. 32: 293-301.

Mitra J (2001) Genetics and genetic improvement of drought resistance in crop plants. Curr Sci India. 80: 758-762.

Mohammadi R, Armion M, Kahrizi D, Amri A (2010) Efficiency of screening techniques for evaluating durum wheat genotypes under mild drought condition. Int J Plant Prod. 4 (1): 11-24.

Mohammadi M, Karimizadeh R, Abdipour M (2011) Evaluation of drought tolerance in bread wheat genotypes under dryland and supplemental irrigation conditions. Aust J Agr Sci. 5(4): 487-493.

Moosavi SS, Samadi YB, Naghavi MR, Zali AA, Dashti H, Pourshahbazi A (2008) Introduction of new indices to identify relative drought tolerance and resistance in wheat genotypes. Desert. 12: 165-178.

Moradi H, Akbari GA, Khorasani SK, Ramshini HA (2012) Evaluation of drought tolerance in corn (Zea Mays L.) new hybrids with using stress tolerance indices. Eur J Sustain Dev 1. (3): 543-560.

Najafian G (2009) Drought tolerance indices, their relationships and manner of application to wheat breeding programs. Middle Eastern Rus J Plant Sci Biotech. 3: 25-34.

Naghavi MR, Pouraboughadareh A, Khalili M (2013) Evaluation of drought tolerance indices for screening some of corn (Zea mays L.) cultivars under environmental conditions. Not Sci Biol. 5 (3): 388-393.
Nouraein M, Abolghasem Mohammadi S, Aharizad S, Moghaddam M, Sadeghzadeh B (2013) Evaluation of drought tolerance indices in wheat recombinant inbred line population. Ann Biol Res. 4 (3): 113-122.

Nouri A, Etminan A, Teixeira da Silva JA, Mohammadi R (2011) Assessment of yield, yield-related traits and drought tolerance of durum wheat genotypes (Triticum turjidum var. durum Desf.). Aust J Agr Sci. 5 (1): 8-16.

Panthuwan G, Fokai S, Cooper M, Rajatasereekul S, O’Toole JC (2002) Yield response of rice genotypes to different types of drought under rainfed lowlands. Part 1: grain yield and yield components. Field Crop Res. 41, 45-54.

Pireivatlou AS, Masjedlou BD, Aliyev RT (2010) Evaluation of yield potential and stress adaptive trait in wheat genotypes under post anthesis drought stress conditions. Afric J Agric Res. 5: 2829-2836.

Rahmani S, Farshadfar E, Jowhar MM (2013) Locating QTLs controlling yield based indicators of drought tolerance in agropyyron using wheat agropyron disomic addition lines. Intl J Agri Crop Sci. 5 (9): 1028-1033.

Rajaram S (2000) International wheat breeding: Past and present achievements and future directions. In: Karow R, Reed B (Eds). Warren E. Kronstad Honorary Symposium, Corvallis, OR, Oregon State University Extension Service, Special Report 1017, June 2000.

Raman A, Verulkar S, Mandal N, Variar M, Shukla V, Dwivedi J, Singh B, Singh O, Swain P, Mall A, Robin S, Chandrababu R, Jain A, Ram T, Hittalmani S, Haefele S, Hans-Peter Piepho H-P, Kumar A (2012) Drought yield index to select high yielding rice lines under different drought stress severities. Rice. (2012) 5:31

Ramirez P, Kelly JD (1998) Traits related to drought resistance in common bean. Euphytica. 99: 127-136.

Richards RA (1996) Defining selection criteria to improve yield under drought. Plant Growth Regul. 20: 157-166.

Robinson HF, Comstock RE, Harvey PH (1949) Estimates of heritability and the degree of dominance in corn. Agron J. 41: 353-359.

Rosielle AA, Hamblin J (1981) Theoretical aspects of selection for yield in stress and non-stress environments. Crop Sci. 21: 943-946.

Saba J, Moghadam M, Ghasemi K, Nishabouri MR (2001) Genetic properties of drought resistance indicates. J Agric Sci Technol. 3: 43-49.

Sio-Se Mardeh A, Ahmadi A, Poustini K, Mohammadi V (2006) Evaluation of drought resistance indices under various environmental conditions. Field Crops Res. 98 (2-3): 222-229.

Talebi R, Fayaz F, Naji AM (2009) Effective selection criteria for assessing drought stress tolerance in durum wheat (Triticum durum Desf.). Gen Appl Plant Physiol. 35: 64-74.

Yan W, Hunt LA, Sheng Q, Szlavnics Z (2000) Cultivar evaluation and mega environment investigation based on GGE biplot. Crop Sci. 40: 597-605.

Yarnia M, Arabifard N, Rahimzadeh Khoei F, Zandi P (2011) Evaluation of drought tolerance indices among some winter rapeseed cultivars. Afr J Biotechnol. 10:10914-10922. 